\title{
Crisis de la democracia. Un recorrido por el debate en la teoría política contemporánea*
}

Democratic crisis. A tour of the debate on contemporary political theory

doi: http://dx.doi.org/10.32870/

María Isabel Puerta Riera*

espiral.v23i65.4454

\begin{abstract}
Resumen
En este artículo se reflexiona sobre la crisis de la democracia actual desde los autores que han sido considerados como centrales en su discusión teórica, sea por sus aportes teóricos o por los debates en los que han intervenido. Para ello, se realiza una presentación de las contribuciones de estos autores, seguida de reflexiones dirigidas a entrelazar las distintas concepciones de la crisis de la democracia. El resultado es un arqueo heurístico que ofrece una perspectiva que busca señalar las posibilidades acerca del desarrollo de la democracia, en medio del escepticismo que la ha acompañado en tiempos recientes $y$ las crisis que envuelven su desempeño, en las que su permanencia como la mejor forma de organización política de la sociedad es puesta en duda, lo que ha propiciado discusiones sobre la calidad de la democracia y su destino como sistema político y modelo ideológico de las sociedades modernas.
\end{abstract}

Palabras clave: democracia, crisis, teoría política, debate, contemporaneidad.

\begin{abstract}
This article reflects on the current democratic crisis considering the authors that have been focal in its theoretical discussion, either for their theoretical contributions or for the debates in which they have intervened. A presentation is prepared of the contributions made by these authors, followed by reflections meant to intertwine the various concepts of the democratic crisis. The result is a heuristic arch that offers a perspective that looks to signal the possibilities regarding the development of democracy, amongst the skepticism that has accompanied it in recent times and the crisis that envelops its development, in which its continuance as the best form of political organization for society is called into question, having spurred discussions on the quality of democracy and its destiny as a political system and ideological model of modern societies.
\end{abstract}

Keywords: Democracy, crisis, political theory, debate, contemporaneity.

\footnotetext{
- Profesora-Investigadora de la Facultad de Ciencias Económicas y Sociales de la Universidad de Carabobo, Venezuela. mpuerta2@uc.edu.ve

* Este trabajo está basado en un capítulo de la tesis doctoral El concepto de crisis de la democracia en la teoría política: ¿en el umbral de la postdemocracia?
} 


\section{Introducción}

El tema de la crisis de la democracia ha estado en el centro de la discusión política contemporánea. La reflexión que aquí se presenta constituye un abordaje teórico de esa noción de crisis en la literatura política actual. En una primera instancia, se introduce la idea de crisis de la democracia a partir de la mirada de autores representativos del pensamiento político contemporáneo que han hecho importantes contribuciones sobre la democracia y las dimensiones de su crisis. En la discusión confluyen argumentos que consideran las relaciones institucionales dentro de la democracia, como el agotamiento en cuanto a su capacidad de control, la ingobernabilidad y la ausencia de participación, la naturaleza sistémica de la crisis, y el déficit de crecimiento democrático.

En la revisión de los diversos argumentos, encontramos interesantes propuestas en relación a las condiciones dentro de las cuales se desenvuelve la crisis de la democracia. Por una parte, se plantea la discusión en relación a la incorporación de la tecnología como metodología democrática; luego, se discute sobre la vuelta a la naturaleza directa de la democracia; y, finalmente, se introducen, como elementos para una redefinición de la democracia, las nociones de postdemocracia, cosmocracia, democracia postliberal, democracia multidimensional y contrademocracia.

En las reflexiones finales se muestra el espacio en donde se articulan las definiciones y las redefiniciones de la democracia, en un intento por rescatar el espíritu de la democracia del desencanto que infunde. Se expresan algunas percepciones y certezas en cuanto al destino de la democracia y su imperiosa necesidad de reinventarse para escapar de la necesidad de ser sustituida o desplazada por opciones que descartan los propios valores democráticos. 


\section{La idea de crisis de la democracia: el debate de los autores}

Es posible encontrar la noción de crisis en la democracia expresada como ausencia de arreglos institucionales o persistencia de conflictos entre sus estructuras. Sin embargo, también se puede abordar dicha crisis como una situación de carencia de valores, los cuales han sido distorsionados, desplazados o descartados. Wolin (2004) introduce el contraste entre el capital y la democracia para presentar la discusión, preguntándose sobre la relación entre la política de las corporaciones y la política democrática, refiriéndose a la noción de crisis como un lugar no explorado debido a que "la ubicación de la crisis se ha buscado en los lugares equivocados" (Wolin, 2004, p. 597). Wolin considera que el error fue suponer que era posible la compatibilidad entre el capitalismo y la democracia, y que estos habrían de evolucionar para permitir la unión entre la cultura del trabajador y su cultura cívica, por lo que afirma que Marx estaba en lo cierto, sólo que parcialmente, pues el capitalismo no solamente desfigura al trabajador, sino que deforma su condición de ciudadano, debido a que las premisas del gran capital operan como factor de estímulo de conductas individualistas, acentuando rasgos personalistas que se distancian de valores como la búsqueda del bien común (Wolin, 2004, p. 601).

En este sentido, Wolin considera que el problema de la democracia es que sucumbe a las redes corporativas en sectores organizados que representan los intereses de grupos que son protegidos por encima del pueblo. De una relación desigual, no puede menos que producirse la desafiliación, que no sólo es un rasgo del Estado postdemocrático, sino postrepresentativo (Wolin, 2004, p. 601). Al respecto, Wolin señala que la democracia (en referencia a la de los Estados Unidos) es efímera, en lugar de representar un sistema 
estable; prefiere denominarla democracia fugitiva para acentuar su naturaleza esporádica, relacionándola directamente con la noción aristotélica. Por ello, resulta mucho más conveniente hablar de formas de democracia en lugar de una sola, pues es esa multiplicidad la que deviene en política antitotalitaria (Wolin, 2004, p. 601). Para Wolin, las posibilidades democráticas dependen de la combinación del localismo tradicional y la descentralización postmoderna. ${ }^{1}$

La democracia como expresión de la organización del poder político ha sido vista por la teoría política contemporánea como una referencia de las sociedades modernas; sin embargo, esa noción se encuentra bajo observación. Para Dahrendorf (2002), no hay duda que la democracia que conocemos como expresión del Estado liberal es sujeta a serios cuestionamientos que hacen necesario repensar su concepción: "Yo diría que ya hemos entrado en una fase que podría definirse como 'la postdemocracia', pero que esto no nos exime de trabajar en la construcción de una 'nueva democracia', sino que más bien nos obliga a ello" (Dahrendorf, 2002, p. 8).

En este sentido, Dahrendorf considera que la democracia descansa en buena medida en la capacidad de los pueblos de construir la institucionalidad democrática, a lo que añade: "sigo convencido de que la crisis actual de la democracia es sobre todo una crisis de control y de legitimidad frente a los nuevos desarrollos económicos y políticos" (Dahrendorf, 2002, p. 11). La necesidad de redefinir la democracia requiere de la búsqueda de nuevas formas de conducir el proceso de gobierno, de toma de decisiones y de cambio en las modalidades de ejercicio del poder, que traducidas como postdemocracia comprenden la "época sucesiva a la democracia clásica” (Dahrendorf, 2002, p. 133).

I. "Democratic possibilities depend upon combining traditional localism and postmodern centrifugalism” (Wolin, 2004, p. 604). 
La democracia en crisis se nos plantea como un modelo que necesita de una redefinición, en virtud de que sus mecanismos tradicionales lucen débiles para garantizar el equilibrio de sus estructuras. El método democrático es el sustituto funcional del uso de la fuerza para la solución de los conflictos sociales (Bobbio, 1985, p. 12). Es por ello que encontramos en el planteamiento de Bobbio sobre los tres estadios del Estado, naturaleza, de derecho y democrático, aportes para la comprensión de la crisis de la democracia, en razón de las motivaciones que incidieron en su evolución de una etapa a otra. Para Bobbio, las amenazas a la democracia vienen de su propio seno, a saber: la ingobernabilidad, la privatización de los espacios públicos y el poder oculto (Bobbio, 1985, p. 14).

En el Reporte sobre la gobernabilidad de la democracia, elaborado para la Comisión Trilateral, se encuentran elementos que apuntan al debilitamiento de la democracia en términos del agotamiento de su lucha, ya no contra los nacionalismos o por la religión o la ideología; cuando el propósito común desaparece, la democracia se debilita, perdiendo su impulso: "El sistema se convierte en una democracia anómica, en la que la política democrática deviene más en una arena para la afirmación de intereses en conflicto que en un proceso para la construcción de propósitos comunes" (Crozier, Huntington y Watanuki, 1975, p. 161). ${ }^{2}$ Las disfunciones de la democracia, según concluye el reporte, se refieren a la deslegitimación de la autoridad, la sobrecarga del Gobierno, la desagregación de intereses y al parroquialismo en el manejo de las relaciones internacionales como los factores que debilitan la democracia.

En Habermas, que coincide con autores como Bobbio, el planteamiento sobre las dificultades de la democracia y los

2. Traducción personal del inglés: "The system becomes one of anomic democracy, in which democratic politics becomes more an arena for the assertion of conflicting interests than a process for the building of common purposes".

Teoría y DEBATE N No. 65 
problemas de su estabilidad sugiere que las primeras no deben buscarse fuera de su institucionalidad, pues es en ella misma donde se encuentran las causas de su propia disfunción. ${ }^{3}$ En relación a la noción de crisis, Habermas hace uso del enfoque sistémico para precisar que ella alude a la incapacidad de los sistemas de sociedad (sistema de sistemas sociales, que se encuentran integrados por sistemas socioculturales y políticos), que no encuentran formas asertivas de responder a las demandas que se les hacen, perturbando su equilibrio interno. Para Habermas, "las crisis surgen cuando la estructura de un sistema de sociedad admite menos posibilidades de resolver problemas que las requeridas para su conservación. En este sentido, la crisis son perturbaciones que atacan la integración sistémica" (Habermas, 1999, p. 21). ${ }^{4}$ Cuando se produce una situación de tal naturaleza, el sistema tiende a colapsar, no pudiendo cumplir con el proceso sistémico, pues entre la sobredemanda y la incapacidad de respuesta, el desequilibrio genera conmoción en sus estados internos.

Ahora bien, no necesariamente los cambios que experimentan los sistemas conducen inevitablemente a una crisis: "Sólo cuando los miembros de la sociedad experimentan los cambios de estructura como críticos para el patrimonio sistémico y sienten amenazada su identidad social, podemos hablar de crisis" (Habermas, 1999, p. 22). En realidad, las crisis pueden ser vistas cuando el cambio amenaza la integración social, cuando las estructuras normativas se ven afectadas, lo que puede conducir a la anomia social: "Los estados de crisis se presentan como una desintegración de las instituciones sociales" (Habermas, 1999, p. 23).

3. En la estética clásica, desde Aristóteles hasta Hegel, crisis designa el punto de inflexión de un proceso fatal, fijado por el destino, que pese a su objetividad no sobreviene simplemente desde afuera ni permanece exterior a la identidad de las personas aprisionadas en él (Habermas, 1999, p. 20).

4. Las negritas son nuestras. 
Es oportuno incorporar el planteamiento que sobre crisis hiciera Koselleck, quien la recordaba en su acepción heredada de la antigua Grecia, como separar, escoger, enjuiciar, decidir; en voz media, medirse, luchar, combatir (2007, p. 241):

Aplicado a la historia, "crisis" es expresión, desde aproximadamente 1780, de una nueva experiencia del tiempo, factor e indicador de una ruptura epocal que, en realidad, medida con el creciente uso del término, aún tendría que haberse intensificado. Pero la expresión continúa siendo tan multiestratificada y oscura como las emociones que dependen de ella. "Crisis" puede, tanto entendida como crónica, indicar "permanencia" como una transición, a plazo más corto o más largo, a mejor o peor, o hacia algo enteramente distinto; "crisis" puede anunciar su retorno, como en economía, o convertirse en un modelo existencial de interpretación, como en psicología o teología. La historia participa de todas las propuestas (Koselleck, 2007, p. 24I).

La crisis es una suerte de invitación a repensar, a revisar aquello que ha dado lugar a una crítica subjetiva, que inevitablemente está ligado a una crisis objetiva, lo que para Koselleck no se puede separar. Pero de esa dinámica (críticacrisis) debe surgir una nueva concepción sobre la realidad que se ha tornado agónica, debilitada en sus cimientos, amenazada en su fundación, porque esta ha quedado diluida en el tiempo por un proceso de desgaste que se va alimentando de las numerosas críticas que se entrelazan para dibujar una misma impresión sobre la crisis. Al respecto, Koselleck señala: “Pero crisis significaba también 'decisión' en el sentido de la realización de un juicio y del enjuiciamiento, cosa que hoy pertenece al ámbito de la crítica" (2007, p. 242), precisamente, porque era necesario reconocer lo que estaba descompuesto. Tiene sentido, según esto, pensar en la crisis, como una "ruptura epocal" en la que ocurre una transición hacia un nuevo estadio, una vez que la crítica 
ha dado lugar a una revisión que conduce a un desenlace, a una resolución.

La noción de crisis también se encuentra en el planteamiento de Gauchet (2008) cuando este concibe razonable entender como crisis de la democracia la resistencia de sectores de la sociedad a las instituciones tradicionales y la búsqueda de una salida alternativa, que puede verse reflejada en opciones extremas, como en el caso de algunos Gobiernos totalitarios que alcanzaron el poder por esta vía. Lo que es un elemento de coincidencia cuando se trata de definir la crisis es que la ausencia de enemigos externos hace de su noción algo mucho más complejo de precisar, dado que existe la convicción de que los problemas de la democracia se producen en su propio seno, coincidiendo con otros autores señalados. La crisis de la democracia puede verse como una crisis de crecimiento, pues lo que le ocurre son un conjunto de transformaciones -crecimiento- que, al no producirse de forma orgánica, desencadenan una serie de profundos desequilibrios, afectando su desempeño (Gauchet, 2008, p. 14).

En otra lectura, Ghéhenno (2000) se pregunta si, ante la desintermediación política, estaremos frente a la decadencia definitiva del sistema democrático o al retorno de la democracia directa. Las condiciones actuales de la sociedad, inmersa en los cambios producto de la globalización, en donde la tecnología juega un papel predominante, llevan a Ghehénno a indagar sobre si lo que se avecina es una ruptura total con la noción de democracia que conocíamos, o si, por el contrario, lo que se nos presenta es la posibilidad de hacer realidad la utopía democrática de la participación a través de los recursos tecnológicos de los que hoy disponemos. Esto puede resultar muy atractivo como discusión, pero, según nos advierte el autor, esa percepción errada sobre la democracia, tanto como mecanismo de control político como por ser expresión de la comunidad política, no conduce a 
pensar que la democracia representativa pueda ser sustituida por una virtual en el ámbito de la globalización, porque los valores de la democracia, en tanto modelo de conducción política, muestran una importante inclinación al intercambio y discusión que la intermediación tecnológica, que sustituye a la de las organizaciones políticas, no se encuentra en capacidad de preservar (Ghéhenno 2000, p. 59).

En esta misma dirección, Sartori (1987) se muestra escéptico ante la posibilidad de encarar la democracia mediante un modelo refrendario electrónico (p. 283), que, aun siendo posible técnicamente, tendría consecuencias desastrosas. El directismo que se plantea con el modelo refrendario suprime la noción de articulación que podemos encontrar en la misma formación de la opinión pública que encarna la democracia electoral, planteando la decisión en ausencia de la discusión (Sartori, 2009, pp. 39-41).

El agotamiento de la democracia debe verse desde la perspectiva de un debilitamiento de su ejercicio, mas no del sistema propiamente. La sociedad naturalmente toma distancia cuando la institucionalidad democrática hace a un lado sus intereses primarios para favorecer los de quienes detentan el poder. En un ambiente de desconfianza o de desmotivación, la clase política hace uso de todos los mecanismos posibles para lograr la participación cívica, que, vista desde la perspectiva de la postdemocracia, se puede expresar en la manipulación massmediática.

Eso configura un escenario donde la democracia está provista de condicionantes diferentes de las que le había proporcionado la modernidad. El debate se centra en establecer si la democracia sigue representando los principios democráticos, o si, por el contrario, la idea de la democracia representativa (liberal) ha sido sustituida por otra forma de relación en la que los valores asociados a la democracia pueden desarrollarse y no quedarse sólo en una aspiración, es decir, la postdemocracia. 
Esta concepción de la democracia puede ser vista como una consecuencia del debilitamiento de los mecanismos de la democracia tradicional, que son los factores de mayor influencia en la percepción de ineficiencia en la respuesta a las demandas de la sociedad. La inercia termina por desplazar el modelo de democracia tradicional de la modernidad, pero ¿es la postdemocracia su sustituto? La discusión actual, tanto en los predios de la ciencia política, como de la sociología y de la economía, apunta en esta dirección, la de una redefinición de la democracia y sus mecanismos institucionales.

De esta forma, la noción de crisis es susceptible de ser objeto de múltiples miradas; es posible encontrar agotamiento, lo que deviene en incapacidad; también frustración, lo que acarrea decepción; y la más común de todas las miradas es la pérdida de legitimidad, que inevitablemente conduce a la ingobernabilidad por la dificultad de responder en un ambiente lleno de desconfianza. Una forma de ver la crisis es abordarla desde la naturaleza misma de la democracia y de sus promesas incumplidas, de la necesidad que tiene de recuperar el control perdido sin caer en la tentación de las salidas autoritarias. Recordando a Lipovetsky (2008), la democracia encierra una paradoja, pues no deja de ser la mejor opción de la que disponemos.

La discusión sobre la demoracia como sistema político y modelo ideológico de las sociedades modernas nos remite al eterno debate sobre la democracia procedimental (nominal o formal) y la sustantiva (valores). Pareciera que es ahí donde radican buena parte de los problemas que asociamos con la crisis de la democracia. Difícilmente podría tener éxito como sistema político una sociedad que no tenga como valores fundamentales aquellos que sustenten el ideal democrático. Suficientes ejemplos tenemos de sociedades llamadas democráticas que periódicamente efectúan elecciones, pero que presentan un balance muy desfavorable cuando son 
evaluadas a través de indicadores que miden sus niveles de gobernabilidad.

La transición hacia la democracia, desde el ideario de una sociedad restringida, dominada por una visión teocéntrica, la refieren Laclau y Mouffe (2006) como una suerte de revolución democrática en la que hubo que operar un cambio de significados y referentes con la adopción de un conjunto de valores que hicieran posible superar el modelo de dominación existente -en el cual la desigualdad y las limitaciones a las libertades individuales eran consideradas como sus principios fundamentales, dadas las exigencias de control social de la época-. Por eso es que con la Revolución francesa (1789) se inicia un periodo de movilización, estimulado por la emergencia de una nueva concepción filosófica que desplaza a la tradicional. La revolución democrática, que comienza con la Revolución francesa, define una nueva legitimidad como su primera experiencia: la cultura democrática. El discurso democrático se presenta como subversivo al denunciar la opresión del antiguo régimen, a lo cual responde esta nueva cultura democrática. $\mathrm{Al}$ respecto, Laclau y Mouffe señalan lo siguiente:

Pero para poder ser movilizado de tal modo, era preciso primero que el principio democrático de libertad e igualdad se hubiera impuesto como nueva matriz del imaginario social -en nuestra terminología: que hubiera pasado a constituir un punto nodal fundamental en la construcción de lo político [...]. Es para designar a esta mutación que, tomando una expresión de Tocqueville, hablaremos de "revolución democrática". Con ella designaremos el fin del tipo de sociedad jerárquica y desigualitaria, regida por una lógica teológico-política, en la que el orden social encontraba su fundamento en la voluntad divina. El cuerpo social era concebido como un todo en el que los individuos aparecían fijados a posiciones diferenciales (2006, p. 197). 
La superación de este modelo tiene lugar a partir de la "democratización" del liberalismo político en el que la democracia influye sobre el modelo de pensamiento liberal, lo que permite alcanzar una articulación entre los valores más importantes de ambas concepciones filosóficas, llegando a convertirse la ideología liberal-democrática en sentido común de las sociedades occidentales (Laclau y Mouffe, 2006, p. 203). Esa unión entre los principios de igualdad (democracia) y libertad (liberalismo), reflejados en la unión entre la equidad y la autonomía, se expresa en el ejercicio de la libertad política y de la participación democrática, que hace crisis cuando es el propio liberalismo el que pone en peligro ese equilibrio al favorecer la defensa de la libertad individual ante la interferencia del Estado (2006, p. 221).

Para Mouffe (1999), el desarrollo de la democracia debe superar la búsqueda de equilibrio entre libertad e igualdad, pues se trata de que la contradicción entre ambos principios contribuye a su fortalecimiento.

Tomar en serio el principio ético del liberalismo es afirmar que los individuos deberían tener la posibilidad de organizarse la vida como lo deseen, de escoger sus propios fines y de realizarlos como mejor les parezca. En otras palabras, es reconocer que el pluralismo es constitutivo de la democracia moderna. En consecuencia, es preciso abandonar la idea de un consenso perfecto, de una armoniosa voluntad colectiva, $y$ aceptar la preminencia de conflictos y antagonismos. Una vez descartada la posibilidad de lograr la homogeneidad, resulta evidente la necesidad de las instituciones liberales (Mouffe, 1999, p. 146).

Una lectura desde la perspectiva latinoamericana sobre la democracia y su crisis la ofrece Santos (2004, p. 9) cuando plantea la discusión desde la noción del contrato social como un instrumento que contiene su propia limitación, debido a que en la medida en que se necesita de la subordinación a la voluntad general para garantizar la equidad, en esa 
medida se produce una limitación a la libertad misma, en lo que destaca, además, la dependencia de la democracia para superar sus debilidades en el desarrollo de su capacidad redistributiva:

Del mismo modo que la ciudadanía se configuró desde el trabajo, la democracia estuvo desde el principio ligada a la socialización de la economía. La tensión entre capitalismo y democracia es, en este sentido, constitutiva del Estado moderno, y la legitimidad de este Estado siempre estuvo vinculada al modo, más o menos equilibrado, en que resolvió esa tensión [...]. Su grado máximo de legitimidad resulta de la conversión, siempre problemática, de la tensión entre democracia y capitalismo en un círculo virtuoso en el que cada uno prospera aparentemente en la medida en que ambos prosperan conjuntamente. En las sociedades capitalistas este grado máximo de legitimidad se alcanzó en los estados de bienestar de Europa del Norte y de Canadá [...]. Este paradigma social, político y cultural [el contrato social] viene, sin embargo, atravesando desde hace más de una década una gran turbulencia que afecta no ya sólo a sus dispositivos operativos, sino a sus presupuestos; una turbulencia tan profunda que parece estar apuntado a un cambio de época, a una transición paradigmática (Santos, 2004, pp. 7-9).

La discusión sobre la democracia se plantea, entonces, desde la lucha entre la visión hegemónica de la construcción democrática y representación democrática elitista, y la contrahegemónica, de innovación social y construcción de una nueva institucionalidad, que se propone como alternativa latinoamericana, desde una concepción participativa de la democracia, a la visión eurocéntrica de la democracia (Santos, 2005, p. 46).

Por su parte, Borón (2003, p. 148) atribuye la preocupación por la crisis de la democracia a la ampliación de derechos frente a los sectores privilegiados, en lo que representa a su vez un reto para la superación de las debilidades que el modelo económico capitalista le transfiere a la democracia: 
Si a esto se suma que el carácter expansivo de la democracia tiende a alienar la lealtad de los sectores burgueses -alarmados porque las luchas populares han transformado la ciudadanía formal y abstracta del Estado liberal en un atributo dotado de contenidos concretos y tangibles-, se podrán comprender muy fácilmente las razones por las que el Occidente conservador instaló en el centro de sus preocupaciones el tema de "la crisis de la democracia".

[...]

La tesis de este trabajo, en consecuencia, es que las frágiles democracias latinoamericanas sólo podrán sobrevivir si tienen la audacia y la sabiduría suficientes como para promover un ambicioso programa de reformas sociales que modifiquen sustantivamente el funcionamiento del capitalismo periférico (Borón, 2003, pp. 148, 183).

Esta es una discusión a la que se añade el debate planteado sobre la demoeleuthería, término introducido por Alonso y Alonso (2015, p. 60) en su abordaje del zapatismo chiapaneco, como una aproximación a la definición de la búsqueda de la libertad de los de abajo:

Consideramos que a este impulso por la liberación desde abajo se le puede denominar demoeleuthería, que en el griego actual se diría dimoelefthería (Márkaris, 2012), pero que en el griego antiguo es demoeleuthería, e implicaría los términos demos (pueblo) y eleuthería (libertad): la libertad popular o de los de abajo. La demoeleuthería no es algo exclusivo ni rígido, sino procesual, y que combina otras dinámicas como esa democracia de los de abajo, esa búsqueda de la justicia, esa solidaridad con los que luchan por su liberación y por el respeto a la naturaleza (Alonso y Alonso, 2015, p. 60).

En estas tres lecturas hay un eje común en la articulación que hacen del modelo político (democracia), que se desarrolla paralelamente al modelo económico (capitalismo), y en cómo los efectos de la subordinación de un modelo al otro condicionan la viabilidad democrática, lo que deriva en 
un planteamiento que Santos concibe como una transición paradigmática, mientras que Borón advierte que el camino a seguir es el reformista (reforma económica), y mientras que Alonso y Alonso lo interpretan como el rescate de la noción de libertad desde las bases mismas de la sociedad.

Es posible entonces pensar la crisis como un malestar producto de lo irreconciliable de dos visiones de la política que por razones históricas se han visto en la necesidad de coincidir para enfrentar amenazas mayores. A decir de Sartori, la democracia ha sido el medio, y el liberalismo el fin; en el siglo XIX prevaleció el elemento liberal, mientras que en el siglo XX el péndulo giró hacia el democrático (Sartori, 1987, p. 386). Entonces, "las dos hebras de la democracia liberal, entrelazadas en el tejido político occidental, se separan en el resto del mundo [en el siglo Xx]; mientras que la democracia florece, el liberalismo constitucional no" (Zakaria, 1997, p. 22). ${ }^{5}$

La crisis de la democracia representativa puede entonces encontrarse en la relación desequilibrada que señala Zakaria, donde el liberalismo constitucional ha conducido a la democracia, pero la democracia no parece aportar al liberalismo constitucional. ${ }^{6}$

En este escenario, los instrumentos de la democracia se debilitan, y, por ende, el poder, haciéndose ingobernable, lo que precipita la necesidad de una figura autoritaria que pueda recomponer la relación Estado-sociedad, y que regule los espacios, público y privado, para que haya equilibrio en sus relaciones (Lipovetsky, 1994, p. 129). El hedonismo, como contradicción cultural del capitalismo, es un rasgo característico de la era postmoderna. El hombre se ha liberado de las ataduras dictadas por los valores considerados tradicionales, y se ha abandonado en un culto que

5. Traducción propia.

6. "Constitutional liberalism has led to democracy, but democracy does not seem to bring constitutional liberalism" (Zakaria, 1997, p. 28). 
comienza por el consumo y termina por la individualidad. Una sociedad que privilegia lo material sobre lo espiritual naturalmente expresa egoísmo, ser una sociedad homocéntrica, haciendo necesario preguntarse ¿cómo se sostiene la democracia en ese contexto?

Sin embargo, Lipovetsky rechaza la idea de que el escenario anticipe el declive de la democracia; por el contrario, en esa práctica hedonista queda claro que no hay desconfianza hacia la democracia. Esto explica que la indiferencia hacia la participación electoral, o en espacios decisorios, no es más que la demostración de aceptación de los procedimientos democráticos, aunque, sin duda, algo despreocupada (Lipovetsky, 1994, p. 129).

La Guerra Fría fue el escenario en donde la noción de democracia se tornó ambigua, pues para unos bastaba con argumentar su rechazo a las fórmulas de izquierda para considerarse una democracia, independientemente de los requerimientos institucionales, mientras que para otros el rechazo al capitalismo era suficiente para llamarse una república democrática (Hardt y Negri, 2004, p. 268).

Para Hardt y Negri, la crisis de la democracia debe verse, por una parte, desde la corrupción y la insuficiencia institucional que predomina en sus prácticas, y, por la otra, en cuanto a su definición propiamente. En su reflexión, está claro que esta crisis está asociada al agotamiento mismo del modelo de la democracia moderna, que en el contexto globalizado pierde sentido, más aún cuando factores que no están sujetos a control por parte del poder político, como el fundamentalismo o el terrorismo, someten a la democracia a fin de preservar la paz y el equilibrio mundial (Hardt y Negri, 2004, p. 268).

Hay dos vertientes o perspectivas a partir de las cuales puede verse la globalización y su relación con la democracia. Están las posturas de izquierda en contra de la globalización, a la que consideran como una amenaza 
para la democracia -socialdemocracia-, y a favor, que consideran a la globalización como una condición propicia para la democracia -cosmopolita liberal-. Por otro lado, las posturas conservadoras presentan la hegemonía global estadounidense como una opción válida para la expansión de la democracia. Los conservadores basados en valores tradicionales se distancian de esa percepción al dudar de la capacidad de la democracia estadounidense de exportarse (Hardt y Negri, 2004, pp. 269-273).

El asunto, tal como lo plantean Hardt y Negri, es que la globalización y sus efectos representan una amenaza para la democracia, insistiendo que el camino conduce hacia la necesidad de una redefinición de la democracia, lo que ya una vez en la modernidad hubo que resolver, y que de nuevo se hace necesario, pero ahora ante el reto de la globalización (Hardt y Negri, 2004, p. 275).

La modernidad introdujo dos importantes innovaciones a la tradición democrática antigua: el carácter universal de la democracia de todos (Hardt y Negri, 2004, p. 277), y la representatividad, como síntesis disyuntiva, al vincular al pueblo con el Gobierno y, a su vez, separándolo (Hardt y Negri, 2004, p. 279). Las grandes decisiones políticas hoy día obedecen a procesos mucho más complejos porque implican la participación de múltiples actores, agrupados en un entramado institucional que responde a mecanismos producto de la propia globalización, lo cual hace del contexto de la democracia un ámbito de mayor alcance.

En este sentido, ¿pueden tomarse decisiones en relación a la economía, la agricultura, la educación, la cultura, o la salud sin considerar el impacto que tienen las mismas en el contexto mundial? Estamos frente a límites que se diluyen, y con ellos el tema de las soberanías adquiere una novedosa interpretación, como, por ejemplo, en el caso de la Unión Europea, donde las soberanías nacionales se distinguen por otros atributos (Calamé, 2009, p. 46). Esto se ve refle- 
jado con mayor fuerza en el propio plano político, cuando decisiones nacionales tienen impacto en el ámbito regional o hemisférico, generando políticas de bloque, tal como ha ocurrido en los casos de Honduras (2009) y posteriormente en Paraguay (2012). ${ }^{7}$

En Tezanos (2002), encontramos que los problemas de la democracia seguirán profundizándose en la medida en que esta no se reinvente para superar las crisis de funciones y de imagen, descritas como los problemas de desconexión entre las demandas sociales y las respuestas del sistema que no son agregadas y articuladas por las organizaciones políticas. Por otra parte, el terreno que han ganado los valores asociados a la antipolítica contribuye en alguna medida a la deslegitimación no sólo de la política propiamente, sino de sus actores, en una suerte de "infrapolítica" (Tezanos, 2002, p. 44).

En otra perspectiva, Rosanvallon (2006) define la contrademocracia como el dominio de un modelo construido sobre la base de la desconfianza, en donde el control se encuentra en manos del pueblo soberano -"democracia del control"-; en este modelo, se multiplican los poderes de sanción y de obstrucción como una segunda atribución de la contrademocracia, dando lugar a una democracia negativa, que luce como una versión opuesta al proyecto original que encarnaba la democracia, así como constituida en torno a un mayor poder del pueblo como juez, en donde se produce una judicialización de la política, representando formas de ejercer la soberanía de manera no tradicional desde una perspectiva institucional (Rosanvallon, 2006, pp. 30-35).

Por su parte, Fotopoulos considera que la sociedad democrática bajo el modelo representativo atraviesa por una profunda y extensa crisis, a la que llama multidimen-

7. En ambos casos, bajo circunstancias revestidas de legalidad, se tomaron decisiones políticas cuestionadas en su legitimidad que propiciaron la reacción de la comunidad hemisférica frente a ambos países.

\section{6}


sional, retratando la debilidad de los valores que dieron sustento principalmente a la idea de progreso en la edad sucesiva a la Ilustración, así como su relación con la noción de crecimiento (Fotopoulos, 2009, p. 149). Para este autor, la crisis multidimensional tiene que ver con la propia universalización de las instituciones modernas. Por una parte, se encuentra la dimensión económica de la crisis, cuyo rasgo más significativo lo constituye la reducción del estatismo y el mantenimiento de la brecha entre las economías del Norte y el Sur, universalizando la exclusión de un sector importante de la población, estimulando migraciones del Sur hacia el Norte.

En otro sentido, se encuentra la dimensión política, que refleja la relación complementaria entre la concentración política y la económica, en donde los modelos económico y político de una dinámica económica agresiva han conducido a esa concentración económica, de igual forma que la dinámica democrática representativa ha favorecido la concentración política. Fotopoulos considera que la crisis de la política se ha desarrollado en la modernidad neoliberal, minando las bases de la democracia representativa y manifestándose en las formas de cuestionamiento hacia instituciones fundamentales, cuestionamientos que pueden encontrarse subyacentes en las expresiones de descontento o aislamiento de formas y prácticas de participación democrática: abstención, protesta y otras expresiones de la antipolítica (Fotopoulos, 2009, p. 154).

Fotopoulos encuentra que la apatía masiva hacia la política puede rastrearse en Castoriadis cuando este hace referencia a lo inadecuado de los programas políticos que contemplan la autonomía como proyecto (Fotopoulos, 2009, p. 155), agregando que la causa de la apatía actual es lo inadecuado de la representatividad democrática para crear unas condiciones genuinamente democráticas. En este sentido, Castoriadis se refiere a que esa idea de autonomía, 
concebida como un fin en sí mismo, se inscribe dentro de una postura meramente formal que no aclara cuáles son sus propósitos, los cuales, sean los que sean, necesariamente requerirán del concurso de todos los ciudadanos (Castoriadis, 2005, p. 129), porque para Castoriadis la autonomía, vista como libertad efectiva -bajo la ley-, es una autonomía colectiva que no puede darse sin el concurso de una autonomía individual, donde la una requiere de la otra para su realización (Castoriadis, 1996, p. 6). Más adelante, señala Castoriadis que "La democracia como régimen es, por tanto, al mismo tiempo, el régimen que intenta realizar, tanto como resulta posible, la autonomía individual y colectiva, y el bien común tal como es concebido por la colectividad considerada" (Castoriadis, 1996, p. 6).

Para Fotopoulos, la dimensión política de la crisis tiene relación con la creciente internacionalización del mercado económico; el debilitamiento del poder de los Estados para controlar los asuntos económicos; la competitividad entre los países, que degenera en el colapso de la democracia social; con el establecimiento del consenso neoliberal y la conversión pragmática, que desaparece las barreras ideológicas entre los partidos políticos; los cambios tecnológicos conducentes a la sociedad postindustrial y a una nueva división del trabajo, que se manifiesta en el debilitamiento de la clase trabajadora y la política tradicionales; $y$, finalmente, con el mito del fin de las ideologías, como consecuencia del colapso de los regímenes socialistas, lo que fortalece la promoción de los valores asociados al modelo neoliberal (Fotopoulos, 2009, p. 156).

La dimensión social, por su parte, se expresa de manera proporcional a la crisis de la economía, principalmente en razón de su crecimiento; en estos términos, la sociedad crece, y con ello sus problemas, disfunciones y debilidades, con el contexto agravado por la expansión del mercado económico en todos los ámbitos de la vida social (Fotopoulos, 2009, p. 159). 
La dimensión cultural de la crisis de la democracia, a su vez, es la consecuencia de los efectos de la economía de mercado sobre los valores y tradiciones culturales, proceso acelerado en el siglo XX con la ampliación de la economía de mercado y su consecuente crecimiento económico, que ha conducido a la homogenización cultural, expresada esta en unos patrones de consumo que alimentan esas conductas: música, moda, consumo, medios, haciendo más simple a la cultura, en un proceso fortalecido por la globalización, anulando culturas con tradiciones, como la europea en materia de cine, que sucumbe a la voracidad competitiva de la industria fílmica de los EE. UU. (Fotopoulos, 2009, p. 161).

Por otra parte, la dimensión ideológica de la crisis puede observarse a partir de los cambios estructurales en la transición hacia la modernidad neoliberal, lo cual se expresa en el auge del irracionalismo de variadas formas: desde los fundamentalismos religiosos hasta la llamada "nueva era". Para Fotopoulos, el ascenso del irracionalismo es un resultado directo de la crisis de crecimiento económico, tanto en el sistema capitalista como en el socialista. El colapso de los proyectos emblema de la modernidad -el socialista y el desarrollista-, además del cuestionamiento a la credibilidad de la ciencia, condujeron al crecimiento del irracionalismo y al ascenso del postmodernismo, dado el auge del neoliberalismo y la crisis ideológica (Fotopoulos, 2009, p. 161).

La dimensión ecológica, finalmente, hace referencia a la responsabilidad del patrón de la economía de mercado y su influencia negativa sobre el medio ambiente, todo esto planteado como alternativa al discurso del desarrollo sustentable, la solución ecodemocrática, que promueve la búsqueda de las causas de la crisis ecológica en el propio sistema social sometido a la dominación institucional de la explotación, trasladándola hacia la necesidad de dominar el sistema ecológico (Fotopoulos, 2009, p. 166). 
Ortega (2006) ofrece una interesante perspectiva con su planteamiento de una cosmocracia, que es la constitución de una definición del modelo en desarrollo desde 1990. La cosmocracia se revela como el régimen político más adecuado para el ámbito global, cuyos rasgos característicos son, por una parte, la concurrencia en el espacio internacional de una diversidad de actores, y, por otra, la conformación de un nuevo sistema político global, en donde se desarrolla una cultura política particular. De este modo, representa un modelo político que evoluciona históricamente, y donde la participación de los ciudadanos se hace mediante sus respectivas organizaciones político-jurídicas (Estado), así como organismos no gubernamentales y actores internacionales (Ortega, 2006, p. 163).

En la visión de cosmocracia de Ortega concurren diversos actores que actúan en el ámbito de la política internacional e influyen decisivamente en su definición. Se hace notar el hecho de que los ciudadanos no participan sino a través de estructuras colectivas, donde además intervienen fuerzas contrarias al interés de desarrollar este sistema político global. Con esto se muestran los límites de lo aceptable y lo no aceptable -lo que se encontraría fuera del círculo de la cosmocracia-, lo que produce una medición de fuerzas centrífugas (Ortega, 2006, p. 167), mientras que, en el sentido inverso, las fuerzas centrípetas contribuyen a afianzar el modelo de la cosmocracia.

La democracia fue, durante mucho tiempo, en el contexto moderno, una fuente de expectativas que, producto de la incapacidad de resolución de las mismas, fue sumiéndose en un laberinto de hostilidades. Para Ghehenno, estas hostilidades son la consecuencia de la ausencia de consenso, 
tanto en lo político como en lo social, y de la dominación de la sociedad por parte del Estado. ${ }^{8}$

Linz (1996) habla de la crisis de la democracia como la incapacidad manifiesta de resolución de problemas por parte del sistema y las oposiciones desleales que se presentan como alternativa y propician la polarización al buscar fuera del Gobierno la solución a los problemas (Linz, 1996, p. 93). Pero la visión de Linz se circunscribe a la lectura procedimental de la democracia como sistema político, cuando estamos en presencia de una crisis que trasciende lo instrumental, considerando que su misma concepción y definición se encuentra bajo escrutinio. Bovero (2002), por otra parte, señala que la democracia se encuentra rumbo al modelo de democracia degenerada gracias a la unión del patrimonialismo y el populismo, así como del personalismo -sea carismático o no-, que legitima por la vía constitucional tales propósitos (Bovero, 2002, p. 160).

Cuando María Zambrano reeditaba en 1987 su obra Persona y democracia, publicada por primera vez en 1958, y en donde señala que la democracia del mundo occidental está cercana a su realización para superar su condición de utopía, estando profundamente ligada a la noción de progreso, la democracia prometía ser el único camino adecuado para el mundo occidental; sin embargo, Zambrano justifica la nueva edición al reconocer que la crisis de occidente, más que crisis, es "orfandad", dejando la obra como "un testimonio, uno más de lo que ha podido ser la historia, de lo que pudo ser; un signo de dolor porque no haya sucedido que no se desvanece la gloria del ser vivo de la acción creadora

8. La democracia liberal se apoyaba en dos postulados, cuestionados hoy: la existencia de una esfera política, lugar del consenso social y del interés general, y la existencia de actores dotados de una energía propia, que ejercían sus derechos, que manifestaban su "poder", antes incluso de que la sociedad los constituyese en sujetos autónomos (Ghehenno, 1995, p. 45). 
de la vida, aun así, en este pequeño planeta" (Zambrano, 1996, p. 13).

Esa misma frustración, a la que ya se ha hecho referencia, se manifiesta como incapacidad para responder o como capacidad autodestructiva: el estado de democracia se autodestruye rápidamente cuando existe sólo fuera del sistema real de Gobierno, o como un periodo interino extraordinario que es sólo una suspensión de ese sistema de Gobierno (Lummis, 2002 , p. 186). Zolo (1994, p. 131) señala las promesas rotas de la democracia, retomando el planteamiento de Bobbio (2003) sobre las falsas promesas de la democracia, relativas al nacimiento de la sociedad pluralista, la garantía de la representación colectiva de intereses, la superación del poder de las oligarquías, la capacidad de ampliar su alcance en el territorio de influencia, la persistencia de los poderes ocultos que influyen en las instituciones, y la ausencia de educación cívica democrática (Bobbio, 2003, pp. 28-40). Sin embargo, Zolo advierte que Bobbio pretende justificar el modelo de democracia mínima, estableciendo una débil frontera entre esta y su caracterización de los regímenes no democráticos (Zolo, 1994, p. 142).

La democracia, para Bobbio, fue un proyecto pensado para otra sociedad, y en la nuestra se encontró con limitaciones: una economía compleja que requiere de una racionalidad técnica de similar naturaleza y el aumento del tamaño del aparato burocrático y su consecuente bajo rendimiento. Sin embargo, Bobbio no es pesimista, y cree que, a pesar de las promesas incumplidas y las dificultades para su desarrollo, no es posible todavía que un régimen democrático degenere en uno autocrático (Bobbio, 2003, p. 45).

Zolo, en cambio, sí se muestra pesimista en relación a la democracia: cree que la preservación de las instituciones democráticas postindustriales se encuentra seriamente amenazada. Además de los factores internos, señalados por Bobbio, están los factores externos que Zolo agrupa como 
expresiones de la complejización del mundo contemporáneo: el crecimiento demográfico, la ampliación de la brecha entre los países desarrollados y subdesarrollados, los países no democráticos, el desarrollo de la guerra en el ámbito nuclear y biológico-químico, el terrorismo y los desequilibrios en el medio ambiente, todas amenazas al orden político democrático, encaminado a una suerte de "melancolía democrática", citando a Castoriadis (Zolo, 1994, p. 224).

En Žižek (2003), por otra parte, se expresa una concepción de la democracia como sistema lógico formal, definido por sus condiciones procedimentales, las cuales son unas reglas de juego que legitiman sus decisiones, decisiones que pueden resultar comprometidas debido a las manipulaciones de las que son objeto por parte del sistema formal de normas, como fue el caso en las elecciones de los Estados Unidos en el año 2000, y, más recientemente, en la destitución del presidente paraguayo Lugo en junio de 2012, casos en los que, bajo argumentos jurídicos, la aplicación de la normativa lució reñida con la convicción política, todo esto en medio de una muy cuestionable legitimidad de los desenlaces de ambos casos.

El planteamiento de Žižek reviste una ácida crítica a la hegemonía de los Estados Unidos, cuyo monopolio de la bandera de la democracia se esgrime para calificar a los regímenes políticos y para imponer dicha forma de gobierno como sistema político, según sean sus intereses. El caso de Iraq, que Žižek revisa en su artículo "Demasiada democracia", refleja la doble moral del discurso democrático, cuyo interés depende del caso y de la conveniencia de la imposición de la democracia como sistema político, amén de la tutela que Estados Unidos ejerce tanto en el caso de Irak como de Afganistán.

Tomando como referencia las ideas de Zakaria en relación al problema que representan la sobredemocratización o la sobredemocracia, Žižek profundiza en su crítica al señalar 
que el republicanismo norteamericano considera que no todas las sociedades están preparadas para la democracia y que, por lo tanto, su desarrollo debe ser un proceso supervisado. Además, siguiendo con la crítica a Zakaria, el problema se hallaría en la excesiva democratización, que le otorga poder a sectores que no tienen la madurez política para ejercerlo. Žižek concluye que esa condición de vigilante de la democracia conduce a la humanidad hacia una nueva Edad Oscura (Žižek, 2003).

\section{Reflexiones finales}

La democracia como etiqueta descriptiva no necesariamente refleja el ideal que históricamente ha representado (Whitehead, 2011, p. 21). En los últimos dos siglos, la discusión ha girado en torno a una democracia que constantemente hace referencia a un modelo que, en el transcurso de veinticinco siglos, ha sufrido cambios significativos, pero que no tiene más relación con la experiencia actual que su denominación.

Se ha abordado la democracia desde una caracterización de la misma en el contexto de la teoría política contemporánea, no como procedimiento sino como modelo, situando la discusión sobre lo que la crisis de la democracia representa en el debate de la modernidad y la postmodernidad. Analizando el contexto epistemológico de la democracia, su evolución y crisis desde la teoría política contemporánea, nos hemos aproximado a la definición de la postdemocracia.

La democracia, nacida en la antigüedad griega, hizo su transición hacia la modernidad, no sin antes superar la desconfianza y resistencia que inspiraba. El modelo que adopta, la representatividad, se concibe como un mecanismo para superar las debilidades que plantea la democracia directa y garantizar el control de sus instituciones, además de fortalecerse por la influencia del modelo económico capi-

\section{4}


talista, con el cual inevitablemente resultaría asociada. Ha sido precisamente esa asociación la que ha conducido a la democracia a experimentar importantes crisis, que, como hemos desarrollado en esta contribución teórica, corresponde a una conjunción de circunstancias que generan más dudas que certidumbres sobre el futuro de la democracia. La representatividad ha transferido su crisis a la democracia misma, haciéndola ver débil ante la amenaza autoritaria, sobre todo en sociedades políticamente inmaduras.

Sin embargo, al observar los problemas de la democracia desde el pensamiento político contemporáneo, la discusión se hace más compleja, porque no se trata del procedimentalismo que tanto preocupa, sino de los valores implícitos en un modo de vida que encarna la democracia misma, y que se ve estremecido por las mismas razones que cuestionan la modernidad. La crisis de la modernidad no deja de verse reflejada en la crisis de la democracia: hay una ruptura, la democracia representativa ya no responde a las demandas de una sociedad que desconfía de quienes habían sido los fiduciarios de su ejercicio soberano.

La crisis del capitalismo sigue teniendo influencia sobre la democracia representativa. Además, sus efectos se dejan sentir cuando se reclama una mayor participación del Estado y se espera su admisión de un compromiso social más efectivo (Estado de bienestar), pero cuando el Estado no puede aumentar el gasto social $-\mathrm{O}$ si ello no es suficiente-, las consecuencias afectan los cimientos de lo que la democracia supone garantizar a toda prueba: libertades individuales y colectivas, seguridad y bienestar, equidad en las oportunidades, convivencia social equilibrada, etc.

La democracia participativa puede ser vista como una de las consecuencias más importantes de las disfunciones de la democracia representativa; sin embargo, no por eso deja de tener sus detractores, que ven en el participacionismo una medida insuficiente para la reconquista del ideal 
democrático (Sartori, uno de los más notables). La participación pretende rescatar algunos de los fundamentos de la democracia originaria, la griega, resultando claro que procedimentalmente es inviable, por lo que su construcción requiere adaptarse a los espacios de una nueva relación Estado-sociedad, marcada por el impacto de la globalización y la ampliación del modelo económico capitalista.

El espacio global, donde, para autores como Held y Ortega, debe consolidarse una democracia mundial, responde a la necesidad de no solamente alcanzar regiones esquivas a la democratización, sino además fortalecer los procesos democratizadores, que son necesarios en la nueva configuración de los Estados que, como la Unión Europea, representan una creciente complejización. Esa nueva realidad geográfica, política, social, cultural y económica requiere de una conducción política que responda a las complicaciones implícitas en dicho entorno.

En el pensamiento moderno, la democracia tardó en establecerse, cargando con el pesado lastre de experiencias pasadas que generaban recelo y desconfianza; sin embargo, el tiempo y las circunstancias habrían de suavizar el ambiente para permitirle afianzarse como el modelo ideal de organización política, sin que estuviera exenta, claro está, de cuestionamientos y dudas con respecto a su realización, esto por estar constantemente sometida a comparaciones con la versión antigua griega.

La democracia moderna fue concebida dentro esas mismas convicciones y, por tanto, la crisis de la modernidad no ha dejado por fuera a la democracia. Algunos autores, como Ghehenno, se preguntan si no será necesaria la vuelta al directismo democrático para salvarla: los autoritarismos la han desafiado, y la participación no ha sido, en el mejor de los casos, una salida favorable para su recuperación. 
La postmodernidad trajo al debate, como lo plantea Young (1998), una reinterpretación del pluralismo democrático, porque es en la política democrática donde confluyen aquellas identidades que han sido desplazadas, encontrándose afinidades y desafíos entre los más diversos actores. Esto ocurre en medio de lo que la postmodernidad concibe como el fin de las certezas, la crisis del orden y la ruptura con una forma de concebir el poder. Los cuestionamientos provienen de sectores diversos, antagónicos, pero que, en circunstancias extremas, tienden a agruparse. Como ejemplo reciente de ello está el movimiento de los indignados, donde convergen las más disímiles motivaciones, unidas en una gran movilización de descontento (Nun, 2011) que reclama igualdad y justicia social, rechazando la voracidad del corporativismo financiero y la supresión de derechos laborales, hasta llegar a la defensa del ecosistema, mostrando el quiebre del espíritu de una época, de los paradigmas modernos. Esto se encuentra en la tradición de lo que señala Mouffe (1999) cuando describe a la democracia radical como la unificación, en la profundización de la práctica democrática, de los movimientos sociales plurales de la sociedad civil, tanto en el Estado como en la sociedad (Young, 1998, p. 491).

La crisis que retrata esa ruptura con el orden tiene diversas lecturas, que hemos recorrido desde la mirada de sus autores. Para unos, es una crisis de control y de legitimidad frente a los nuevos desarrollos económicos y políticos (Dahrendorf), mientras que, para otros, la crisis se presenta en lo interno, amenazada desde las propias entrañas de la democracia (Bobbio). La crisis es el producto de un agotamiento por el cese de luchas (Comisión Trilateral) o por la caducidad del modelo (Hardt y Negri), aunque también puede ser vista como una crisis de crecimiento (Gauchet). Es posible que las crisis de funciones e imagen pesen a la hora de buscar los porqués (Tezanos); sin embargo, la noción de una contrademocracia podría explicar por qué 
de súbito caemos en la desconfianza hacia la democracia (Rosanvallon).

En la crisis hay elementos de autodestrucción de la democracia (Lummis); una multidimensionalidad, que no permite argumentar sobre la base de una causa única. Sin embargo, es en la propia incapacidad de la democracia de satisfacer las demandas sociales (Linz) donde se concentra toda la crítica al modelo. En el ámbito latinoamericano, el debate no escapa a la confrontación centro-periferia, en la que hay un agotamiento del modelo contractualista (Santos), lo cual exige una redefinición del modelo (Borón) en la que se encuentren reflejados los sectores sin acceso al poder (Alonso y Alonso).

El problema es que la crisis de la democracia ha trascendido lo meramente procedimental: no es la democracia electoral la que por sí sola puede garantizar la credibilidad en el sistema. En realidad, son los valores que subyacen al ejercicio democrático los que le conceden el soporte necesario para resistir las exigencias que, en muchos casos, resultan disímiles o antagónicas en una misma realidad social.

La crisis de la democracia no es una crisis de su denominación: es de su naturaleza, de su estructura, de sus componentes y de sus principios; es decir: de la metafísica de la democracia. Las realidades políticas, económicas, sociales y culturales no son las mismas que acompañaron a la democracia moderna en su consolidación, de allí que la naturaleza de la democracia no se corresponda con el contexto en el cual se inserta. Sus niveles de acción han ido ajustándose a las demandas por una mayor participación. Sin embargo, esto tampoco ha sido suficiente para recuperar la confianza en sus acciones, haciéndola lucir a veces como un sistema que obstaculiza el verdadero ejercicio de la soberanía (estructura). Los elementos asociados a la democracia, para garantizar su propósito, pueden entrar en cuestionamiento al producirse una pérdida de legitimidad, como 
pasa con los sistemas electorales, legislativos o judiciales (componentes). Los valores (principios) asociados a la democracia, y las instituciones que los representan -Estado de derecho, libertad, equidad, justicia-, son los pilares sobre los cuales descansa la legitimidad democrática; si alguno de estos valores se resquebraja, la democracia pierde terreno como modelo de vida.

La democracia se ha reinventado. La participación, la ciberdemocracia, la democracia mundial, la cosmocracia, no son sino manifestaciones de un deseo de renovación que, sin embargo, muestra la voluntad de restauración de su fachada, no de sus cimientos, en los que creemos están los grandes desafíos democráticos: la concepción el Estado y de su relación con la sociedad, los nexos con la economía, la corresponsabilidad con las demandas sociales, la apertura de espacios de decisión pública transparentes, el reconocimiento de mecanismos de vigilancia y seguimiento, la responsabilidad de la gestión pública, y la participación en las decisiones públicas de forma efectiva, son tan sólo algunos de los más importantes aspectos de la democracia que revisten particular inquietud, esto según los estudios de opinión sobre la democracia efectuados por organismos multilaterales como el Programa de las Naciones Unidas para el Desarrollo, por ejemplo.

Esto significa, que estamos frente a una necesaria redefinición de la democracia, porque la que hemos conocido no ha logrado superar las demandas de renovación de las que hemos hablado. La denominación de democracia ha servido para que muchos regímenes antidemocráticos se revistan de legitimidad, haciéndola aún mucho más vulnerable a las críticas. La democracia debe tomar distancia de una concepción de su modelo que ha trascendido sus raíces.

Sin embargo, en la democracia persiste el deseo de sobrevivir, resistiéndose a sucumbir ante los autoritarismos, mostrándose desafiante en una suerte de renacimiento de 
sus cenizas, en una forma de resurrección como postdemocracia, como lo que surge cuando se han exorcizado todos sus demonios.

Fecha de recepción: 26 de enero de 2015 Fecha de aceptación: 07 de octubre de 2015

Bibliografía

Alonso, C., y Alonso, J. (2015). En busca de la libertad de los de abajo: la demoeleuthería. Guadalajara: Universidad de Guadalajara.

Bobbio, N. (1985). "La crisis de la democracia y la lección de los clásicos”, en N. Bobbio, G. Pontara, y S. Veca, Crisis de la Democracia (pp. 5-25). Barcelona: Editorial Ariel S.A.

(2003). El futuro de la democracia. México: Fondo de Cultura Económica.

Borón, A. (2003). Estado, capitalismo y democracia en América Latina. Buenos Aires: CLACSO.

Bovero, M. (2002). Una gramática de la democracia. Contra el gobierno de los peores. Madrid: Editorial Trotta.

Calamé, P. (2009). Hacia una revolución de la gobernanza. Reinventar la democracia. Santiago: Ediciones LOM.

Caminal, M. (2005). "La política como ciencia”, en M. Caminal (ed.), Manual de Ciencia Política (pp. 19-36). Madrid: Editorial Tecnos.

Castoriadis, C. (1996). "La democracia como procedimiento y como régimen". Iniciativa Socialista, (38). Recuperado de: http://www.inisoc.org/indtodo.htm

- (2005). Los dominios del hombre: las encrucijadas del laberinto. Barcelona: Editorial Gedisa.

Crouch, C. (2004). Posdemocracia. Madrid: Taurus-Santillana Ediciones Generales.

Crozier, M., Huntington, S., y Watanuki, J. (1975). The Crisis of Democracy. Report on the Governability of Democracies 
to the Trilateral Comission. Nueva York: New York UniBibliografía versity Press.

Dahrendorf, R. (2002). Después de la democracia: Entrevistado por Antonio Polito. Barcelona: Editorial Crítica.

Fotopoulos, T. (2009). The multidimensional crisis and inclusive democracy. EE. UU.: INID.

Gauchet, M. (2008). La democracia. De una crisis a otra. Buenos Aires: Ediciones Nueva Visión.

Ghehénno, J. (2000). El porvenir de la libertad. La democracia en la época de la globalización. Buenos Aires: Editorial Paidós.

Habermas, J. (1999). Problemas de legitimación en el capitalismo tardío. Madrid: Ediciones Cátedra.

Hardt, M., y Negri, A. (2004). Multitud. Guerra y Democracia en la era del Imperio. Caracas: Editorial Debate.

Koselleck, R. (2007). Crítica y Crisis. Un estudio sobre la patogénesis del mundo burgués. Madrid: Editorial Trotta.

Laclau, E., y Mouffe, C. (2006). Hegemonía y estrategia socialista. Hacia una radicalización de la democracia. Argentina: Fondo de Cultura Económica.

Linz, J. (1996). La quiebra de las democracias. Madrid: Alianza Editorial.

Lipovetsky, G. (1994). La era del vacío. Ensayos sobre el individualismo contemporáneo. Barcelona: Editorial Anagrama.

- (2008). La sociedad de la decepción. Entrevista con Bernard Richard. Barcelona: Editorial Anagrama.

Lummis, D. (2002). Democracia radical. Buenos Aires: Siglo XXI Editores.

Mouffe, C. (1999). El retorno de lo político. Barcelona: Paidós. Nun, J. (20II). "La bronca de los indignados: causas y reclamos de un fenómeno que conmueve al mundo". La Nación. Recuperado de: http://www.lanacion.com. ar/ | 4 I 9643-la-bronca-de-los-indignados

Ortega, M. (2006). Cosmocracia: política global para el siglo XXI. Madrid: Editorial Síntesis. 
Bibliografía

Rosanvallon, P. (2007). La contrademocracia. La política en la era de la desconfianza. Buenos Aires: Ediciones Manantial.

(2006). "La historia de la palabra 'democracia' en la época moderna”. Estudios Políticos, (28). Recuperado de: http://bibliotecavirtual.clacso.org.ar/ar/libros/colombia/ iep/28/01\%20rasanvallon.pdf

Sartori, G. (1987). The theory of democracy revisited. Part Two: The classical issues. New Jersey: Chatham House Publishers.

(2008). Homo Videns. México: Editorial Taurus.

(2009). La Democracia en 30 lecciones. Bogotá: Editorial Taurus.

Santos, B. (2004). Reinventar la democracia. Quito: Ediciones Abya-Yala e Instituto Latinoamericano de Investigaciones Sociales-FES.

- (2005). "Introducción: Para ampliar el canon democrático”, en, Democratizar la democracia. Los caminos de la democracia participativa (pp. 35-76). México: Fondo de Cultura Económica.

Tezanos, J. F. (2002). La democracia incompleta. El futuro de la democracia postliberal. Madrid: Editorial Biblioteca Nueva.

Whitehead, L. (20I I). Democratización. Teoría y experiencia. México: Fondo de Cultura Económica.

Wolin, S. (2004). Politics and Vision. Continuity and Innovation in Western Political Thought. New Jersey: Princeton University Press.

Young, I. M. (1998). "Political Theory: An overview", en R. E. Goodin, y H. Klingemann (ed.), A New Handbook of Political Science (pp. 479-502). Nueva York: Oxford University Press.

Zakaria, F. (1997). "The Rise of Illiberal Democrac". Foreign Affairs, (noviembre-diciembre), 22-43. Recuperado de: 
http://www.foreignaffairs.com/articles/53577/fareedBibliografía zakaria/the-rise-of-illiberal-democracy

Zambrano, M. (1996). Persona y democracia. Madrid: Ediciones Siruela.

Žižek, S. (2003). Demasiada democracia. EE. UU.: Columbia University. Recuperado de: http://www.lacan.com/ toomuch.htm

Zolo, D. (1994). Democracia y complejidad. Un enfoque realista. Buenos Aires: Editorial Nueva Visión. 